\title{
The Effect of Information Overload on Charity Donations
}

\author{
Petri Kajonius
}

Department of Psychology, University of Gothenburg, P.O. Box 500, SE 40530 Göteborg, Sweden

\begin{abstract}
This study examines the effect of information overload, due to information about people in increasing extent and number of needs, on altruism, such as charity giving. Information overload has previously been conceived in terms of quality as well as quantity of information. The former is conceptualised as extent of need and the latter as number of needs in the present research design. Two studies were conducted to test the prediction that information overload and charity donation size are inversely related. Study 1 was designed according to a 2 x 2 factorial design: Number of needs (high vs. low) x Extent of needs (long term and large scope vs. short term and small scope). Study 2 used a modified similar approach manipulating only number of needs. A sample of 60 and 44 undergraduate students filled out a charity donation form in the two studies. The results show a significant relationship between the factors of extent of need and number of needs with amount of money pledged for charity. People gave less the greater the extent of the need and the greater the number of needs. Both studies suggest information increase about extent and number of needs has inhibiting effects on charity giving. This effect, attributed to information overload, is labelled moral exhaustion.
\end{abstract}

Keywords Altruism, Charity, Moral Exhaustion

\section{Information Overload}

Up till fifty years ago information was only thought of as of great value. Around the time of the Second World War and the rapid development of technology, not only did human beings invent machines with a whole new power and complexity, but they also began to produce information at a larger scale than ever before. Today information production is accelerating beyond our capacity to process it and there is no likelihood that we will ever catch up[1]. Consider for instance these facts: More new information has been produced within the last three decades, than in the last five millennia. Over 9,000 periodicals are published in the United States each year. More than 1,000 books are published daily around the world. In every 24 -hour period approximately 20,000,000 words of technical information are being recorded[2]. In 1969 four computers formed what today is known as the Internet. The number of web servers at the turn of the century was over 45 million with 200,000 added every day[3]. Arguably, this accelerating production of information is affecting us considerably. This paper sets out pondering the effects of this rising tide of information. A concept emerging out of this escalating trend is information overload, a notion commonly discussed in information science and computer science. In trying to define information overload, information can be seen as

* Corresponding author:

petri.kajonius@his.se (Petri Kajonius)

Published online at http://journal.sapub.org/ijpbs

Copyright (C) 2014 Scientific \& Academic Publishing. All Rights Reserved "data" or "facts"[4] and refers to transmittable knowledge, through verbal, visual, or written means of communication. Overload, on the other hand, refers to the transmission of information suggesting a state of imbalance between information input and adequate processing capabilities. Within the field of psychology, information overload is not discussed much. Instead, the focus has been on sensory overload, loosely defined as the reception of more stimuli than what is possible to adequately process[5]. Information overload differs from sensory overload in that it concerns the mental processing effects of being exposed to large amounts of facts and data (knowledge), often resulting in decreased efficiency in thought and action.

Literature on information overloads[3], borders and overlaps with literatures on burnout[7][8]. Information overload at work is a major cause of burnout[8], only to be fuelled by other factors of exhaustion, such as lack of control, lack of feedback or lack of motivation. Literature dealing with these issues within psychology focuses mostly on the work environment. Unfortunately, there is not much experimental psychological research focusing on the element of information overload. As implied however, several good books on the subject can be found, contributing with classifications and typologies[10][9][8].

There seems to be an unspoken consensus in the literature to conceptualise information overload in terms of two dimensions, quantity and quality of information. The dimension of quantity includes the rates, frequencies, and amounts of data received and processed[10]. Rate is the speed by which information is delivered to a recipient, and frequency refers to how often certain information is 
encountered in terms of regularity and persistence. An example of rate is handling a high flow of information, such as receiving constant phone-calls and other types of information at works and an example of frequency is exposure to information with regularity over time, such as going to a busy office every day. The third aspect, amount of information, is what this study is concerned with, and which is operationalized for experimental purposes as meaning the factual number of data received by a processor. For instance, brevity of phone calls and low number of facts could make high rates and high frequencies bearable. The dimension of quality includes relevance, validity and readability[10], which relate to the contents and character of the information. Relevance, which is another aspect this study focuses on, pertains to the contents of the information. Certainly, one type of information may contain data more relevant and impacting for the processor, as compared to data contained in other information. Examine for instance the mental demands on processing the news of the death of a loved one, compared to hearing he or she having a cold. High relevance indicates high importance, both emotionally and cognitively. The second aspect, validity, involves the correlation between received data and needed data, i.e. the true usefulness of what is being handled, while readability refers to the aspect of the organisation of the information to be processed. Plainly put, not many people like unintelligible or irrelevant information to come their way.

Taking the clarification of information overload further, the preconditions and consequences need to be taken into consideration.[6] suggests three types of preconditions when information overload can occur: Inability to process the information at hand, Feelings of overwhelmingness by the information to be processed, and Inability to find certain information. All three preconditions are naturally related to the dimensions of quantity and quality of the information. The inability to process and the feelings of overwhelmingness can be inferred from any of the aspects mentioned (rate, amount, frequency, relevance, validity or readability). The first precondition could also be reformulated as having difficulties making sense and order of the information, while the second precondition deals with tendencies of emotional exhaustion, which is one of the purposes of this research to simulate. Note also, as indicated in the third precondition, that overload paradoxically also can be said to occur with a lack of data.

\section{Moral Information Overload}

Morality is in this study defined as that which has to do with law or convention, and that moral is directed and based on own conscience, group norms, and traditions. Another more psychological definition of morality states that "moral is a set of principles or ideals that help to distinguish right from wrong, to act on this distinction, and to feel pride in virtuous conduct and guilt for violating one's standards" ( $p$. 568.[11]. From these definitions follow that the term moral information can be defined as facts or data that form the basis for distinguishing right from wrong for the purpose of engaging in behavior of own choosing. This study focuses on the moral kind of information pertaining to facts about neediness of other people. It relies on the assumption that most people would consider helping others when faced with the opportunity and agree that helping the needy is the right thing to do. The premise is that moral kind of information, such as dealing with neediness of others, naturally affects people. This is due to factors such as social empathy and altruistic norms. After assessing a plight of needy people in a critical situation, people are believed to act on opportunity and ability to intervene. Perhaps contrary to everyday intuition, the thesis promoted in this paper is that moral information in larger quantities and qualities will not increase altruistic acts, but instead have a decreasing effect. In other words, if too compelling moral information, qualitatively or quantitatively, is received, information overload could occur with the subsequent feelings of exhaustion and decreased efficiency mentioned. Other, more long-term symptoms of overload due to moral information have been described and termed as moral disengagement[12]. This could be seen as a decrease in alertness and efficiency to a point where desensitisation has set in, which often takes time to develop. Bandura used the example of terrorism to discuss how desensitisation seems to work as a defensive-mechanism of coping with for instance an overload of terror threats. Others have described other disengaging mechanisms, such as moral exclusion[13]. Moral exclusion is the unconscious tactic of the mind to exclude certain kinds of moral information as not being encompassed within one's own sphere of responsibility. These are examples purporting to describe the mental strategies people use to avoid information overload, due to moral information.

\subsection{Moral Exhaustion}

What are the effects of information overload, i.e. what characterizes a person suffering from overload from a psychological standpoint? What would be an appropriate label for the kind of information overload, which is due to a surplus of moral information? Decreased efficiency has already been hinted as one of the effects.[8][15] have proposed three salient effect categories: Emotional exhaustion, Decreased efficiency, and Personality change. Emotional exhaustion includes the feelings of tiredness and often helplessness, characterized by low levels of energy, and if unchecked this eventually might lead to withdrawals and social isolation[7]. The second category deals with perceived inadequacy and lessened motivation, resulting in decreased efforts. The last category is the gravest with a more permanent mood change consisting of strong feelings of frustrations and high levels of cynicism following. Thus, according to the literature, being in a condition of perceived inadequacy and feelings of overwhelmingness due to certain aspects of information, tendencies of emotional exhaustion 
with subsequent decreased efficiency could take place. The state of information overload caused by moral information, could appropriately be called moral exhaustion. The purpose of this study is to empirically test if information overload negatively affects willingness to engage in altruistic acts such as charity giving. This effect is labeled a moral exhaustion effect.

\subsection{Altruism}

Altruism can be defined as the act or intention of benevolence engaged in towards others[14]. Research on altruism sparked aflame with the infamous Kitty Genovese case[16]. Social psychologists revealed the power of the situation to the public who had turned away with disgust from the unresponsive bystanders. People's failure to aid in a situation where their help would have significantly relieved the needy person touches on the topic of this paper: How does relevance and amount of moral information correlate with degree of helping? Research on altruism has examined variables such as sex, age, mood, way of asking, type of groups and group size, resulting in useful terms such as diffusion of responsibility, bystander effect, informative conformity etc[17]. No research has been done on failure to help due to moral exhaustion tendencies. Surely, one reason is that moral exhaustion is difficult to operationalize and study experimentally. Most of the existing exhaustion theories come from the research on burnout and sensory overload. Research conducted by Milgram (1970) demonstrated a lower tendency to help strangers, when exposed to large amounts of stimuli such as busy intersections and noisy neighbourhoods. A study in the Netherlands[22] showed positive correlations between levels of environmental input and helping, revealing the importance of being able to focus properly on the need. The present study suggests that the concepts of moral information, information overload, and moral exhaustion are useful in explaining failures to help.

Considerable research has focused on donations to charity, and factors such as influence of a picture, way of asking, aid worker's appearance etc, have all been thoroughly studied[18][19]. However, no research seems to have proposed a link between the quality and quantity of information to donation size. The purpose of this paper is to suggest propositions and producing empirical results exploring this link. One relevant study that has come close to these issues is[19]. They conducted a vignette study varying the wordings of a Red Cross donation request form, showing that empathy and perspective taking were important factors contributing to donation willingness. Some indications that the scope of the need situation affected the size of donations were also found.

\subsection{Research Purpose}

To summarize, this paper reflects on the effects of the mentioned tidal wave of information in our society on altruistic contexts. Moral information and moral exhaustion are introduced as concepts to supplement information overload. The study sets out to focus on how quality and quantity of information about severe needs of hurting people affect helping. The dimensions of relevance and amount of information were chosen for being basic and naturally manipulated within the parameters of a first experiment concerning charity donation size. The third aspect, amount of information, is what this study is concerned with, and which is operationalized for experimental purposes as meaning the factual number of data received by a processor. Relevance, which is another aspect this study focuses on, pertains to the contents of the information. The second precondition deals with tendencies of emotional exhaustion, which is one of the purposes of this research.

This study focuses on the moral kind of information pertaining to facts about neediness of other people. It relies on the assumption that most people would consider helping others when faced with the opportunity and agree that helping the needy is the right thing to do. The purpose of this study is to empirically test if information overload negatively affects willingness to engage in altruistic acts such as charity giving. This effect is labeled a moral exhaustion effect.

The present study suggests that the concepts of moral information, information overload, and moral exhaustion are useful in explaining failures to help. The paper proposes a link between the quality and quantity of information to donation size. The purpose of this paper is to suggest propositions and producing empirical results exploring this link.

\section{Study I}

\subsection{Research Design}

The objective of Study 1 is to examine the effects of levels of moral information on altruistic acts, such as helping the needy. To operationalize this according to the criteria of information overload made by[6], the design needs to create cognitive processing difficulties and overwhelming sensations due to the relevance and amount of information concerning need. For a successful attempt of simulation in the design, subjects have to be exposed to various amounts of information overload. Study 1 seeks to simulate this by forming an empirically testable variable out of the theoretical relevance of information (quality) component by varying the extent of mentioned needs on a donation request letter. A second variable for the experiment is derived from the (quantity) component of amount of information by varying the number of the mentioned needs on a donation request letter. The manipulation of extent is done by altering the level of persistence of need over time and the scope of need geographically, to achieve greatest impact. It is predicted that both these components of information bear significant relevance for subjects' assessment of the need situation and thus affecting the amount pledged to charity. The experiment is a full $2 \times 2$ factorial design where Extent of need (high vs. 
low) and Number of needs (high vs. low) vary. The expectation is that different extents and numbers of needs will produce different levels of overload (moral exhaustion), which in turn will show in inclination to help, in this case donating money to charity. In other words, the greater the extent and number of needs, the smaller amount of money will be donated to charity. The study predicts a main effect for each of the two factors: Subjects reading about a high extent of needs will donate less than subjects reading about a low extent of needs (Hypothesis 1). Secondly, subjects reading about a large number of needs will donate less than subjects reading about a small number of needs (Hypothesis 2). Additive effects between number and extent are also predicted: Subjects reading about a combination of a large number and high extent of need will produce the least amount of donation (Hypothesis 3). Subjects reading about a combination of a small number and low extent need will produce the largest amount of donation (Hypothesis 4).

\subsection{Method}

The method used in the study is the vignette technique or factorial survey[20]. The vignettes were designed in the forms of charity letters asking for a donation. The scenario chosen depicted an aid situation in Ethiopia and was based on actual happenings. The descriptions were of such nature that most people intuitively would agree the morally right thing to do was to donate a sum of money. This premise was however not tested, but the operationalization was successful in that people were willing to donate.

\subsubsection{Subjects}

A sample of 60 undergraduate students (16 men and 44 women, ages 15-55) at the University of Skövde was handed a charity letter with a donation request form. Subjects were randomly assigned to one of four charity letters, which differed in descriptions of need according to manipulations.

\subsubsection{Materials}

The scenarios described situations of need and were followed by requests for monetary donations (Appendix A). A fictitious description was chosen to avoid the activation of preconceived attitudes of the text. The situation of the needy was carefully portrayed as an extreme emergency. The victims lacked control over their situation and were not responsible for their predicament. Their plight would be significantly relieved if subjects chose to donate money. The aim was to elicit feelings of empathy in subjects by exposing them to moral information and to produce various degrees of moral exhaustion. There were four different versions of the scenario described in the charity letters, one for each experimental condition. The letters contained an introductory presentation of the situation (identical for each condition), followed by a description of the need (containing manipulations of number and extent) and finally a request for assessment of a just donation amount.
Furthermore, an attached form asked for standard questions such as age and sex, as well as mood, perceptions of the nature of the need and effectiveness of helping, functioning as manipulation checks (Appendix A). The information manipulating the independent variables related to the plight of an Ethiopian village. The quantity manipulation was varied through need description on the forms stating a large number of needs (high number) or just a few needs (low number). Manipulating the quality variable was achieved through information focusing on the widespread nature of need over time and area (high extent) or just mentioning the temporal predicament of one village (low extent). To ensure subjects' reading of the entire material and thereby the exposure to moral exhaustion, key questions concerning understanding of the charity letter were asked.

\subsubsection{Procedure}

Subjects were randomly assigned to one of four charity letters with a brief verbal explanation of the study being a survey measuring justice assessments in altruistic situations. A consent form and a questionnaire form were attached to the charity letter (Appendix A). A promise with update on results was the only incentive for the subjects. The study was carried out at the University of Skövde as part of class exercise.

\subsubsection{Dependent Variables and Manipulation Checks}

Three dependent variables of donations were measured, each with a slightly different angle on giving. The first was pledged amount of donation according to current circumstances and personal economy (Charity 1), to simulate a true situation as well as possible. The second variable was suggested amount of money for donation after a lottery winning of a sum of SEK10,000 (Charity 2), purposed to give subjects a pot of unexpected cash, not tying them down to personal economic boundaries so much when deciding charity sum, giving more of an idea of the factual willingness to donate. Thirdly, amount of money subjects believe would be contributed by others in the same situation (Charity 3), believed to at least reveal the self-serving bias effect. Subjects were free to put down any amount, but were asked to consider how much they would realistically donate in real life. To ascertain the plausibility and the effectiveness of the manipulations, subjects were presented with a questionnaire form measuring perceptions of need amount, need extent, need scope, need persistence, mood, and feelings of perceived effectiveness of helping. The questions were answered on a scale ranging from 1 (very low) to 7 (very high). Questions were formulated as: How widespread is the crisis situation referred to in the donation form? How would you best describe the time aspect of the need (short term to long term)? How severe is the crisis situation referred to in the letter? Also, information about sex and age of participants were gathered, mainly for statistical purposes, but also for intended post hoc analyses of possible differences. The control question 
on perceived effectiveness was used to ruled out for this to be the explanation for possible differences in results between the four manipulation conditions, $F(3,56)=1.27$, $\mathrm{p}=.29$. No significant mean differences were found in perceived effectiveness depending on conditions Extent of Need, $F(1,58)=.04, p=.84$ nor Number of Need, $F(1,58)=$ $1.17, \mathrm{p}=.28$. The discussion section of this paper will further elaborate on this.

\subsection{Results}

Responses to the items testing the effectiveness of the manipulations, looking for the effects of number and extent, were analysed in a $2 \times 2$ analysis of variance.

Extent of need: Subjects in the high extent condition rated the extent of need perception higher $(\mathrm{M}=6.13)$ than those in low extent condition $(\mathrm{M}=5.55)$ and yielded a significant main effect due to the need extent manipulation $(\mathrm{F}(1,58)=5.11, \mathrm{p}<.05)$. More specifically, there were strong main effects of the need extent manipulation on subjects' perceptions of the geographical scope of need $(\mathrm{F}(1,58)=22.83, \mathrm{p}<.001)$ as well as respondents' ratings of time-duration of need $(\mathrm{F}(1,58)=27.55, \mathrm{p}<.001)$.

Number of needs: Ratings of perceived number of needs due to manipulation of number of needs did not yield a significant main effect, although ratings in high number of needs condition $(\mathrm{M}=5.80)$ were higher than those in low number of needs condition ( $\mathrm{M}=5.50)$. Moreover, according to the intuition that large number would yield less perceived effectiveness of contribution, people in the low need condition also rated their perceived effectiveness of helping as higher $(\mathrm{M}=4.10)$ than those in high need condition $(\mathrm{M}=3.67)$, also non-significant. The conclusion from these checks is that the manipulations embedded in the charity request letters were sufficiently strong on the part of the extent manipulations, but weaker on the number of needs manipulations.

\subsubsection{Effects of Extent and Number}

A multivariate analysis (MANOVA) performed on all three dependent measures (Charity1, Charity2, and Charity3) showed a significant main effect of extent of need $(F(3,54)=3.82, p=.01)$, while number of needs produced a non-significant effect.

Table 1 shows an overview of mean donations in each experimental condition of the three dependent variables of charity, revealing the predicted trends. Average donation size (Charity1, the main dependent variable) in Swedish currency was SEK211 (SD=137, N=60). A 2 x 2 analysis of variance (ANOVA) yielded a significant main effect of extent of need on donation size $(F(1,56)=7.50, p<.01)$. Mean amounts of donation were SEK257 in the low condition of need extent and SEK168 in the high extent condition. Concerning number of needs, following the non-significant effects on the manipulation checks, a non-significant main effect on Charity1 was found $(F(1,56)=3.10, p=.08)$. Though, according to prediction, a notable difference in means was found (low number of needs, SEK238 and high number of needs, SEK138). The results support Hypothesis 1 and show a predicted trend for Hypothesis 2, although not with enough statistical significance.

The two other measured dependent variables (Charity 2, donations after lottery, and Charity 3, other's donations) also varied significantly in relation to the independent variable of extent of need. Charity 2 differed SEK2031 to SEK998, $(\mathrm{F}(1,56)=5.30, \mathrm{p}<.05)$ and Charity 3, SEK249 to SEK152, $(\mathrm{F}(1,56)=6.74, \mathrm{p}=.01)$. Number of needs again failed to produce a significant main effect but resulted in clear differences in means, SEK1660 to SEK1335 (charity 2) and SEK206 to SEK191 (charity 3). These results once more support Hypothesis 1 and while Hypothesis 2 are not met with statistical significance; the data show a trend according to prediction.

\subsubsection{Sex and Age}

The analysis showed a significant effect for $\operatorname{sex}(\mathrm{p}<.05)$ only on Charity3. Men believed that others would give SEK142, while women predicted a considerably larger sum, SEK217. A similar significant effect of sex $(p<.05)$ was found on mood change, which is how much subjects perceived and stated own change in mood after taking part of the moral information provided. Women stated feeling more moved $(M=4.0)$, while men stated lower $(M=3.2)$.

Subjects were divided up into three age groups: 15-25 $(n=24), 26-35(n=26)$, and $35<(n=10)$. An one-way ANOVA analysis showed a significant effect of age on perceived efficiency of helping, $(\mathrm{F}(2,57)=2.50, \mathrm{p}<.05)$. Age was linearly related to perceived impact of own helping. The older the subject the more they perceived their donation as effective. No further conclusions can be drawn from this at this point. A second finding relating to age was its effect on perceived time duration of need, $(F(2,57)=3.13, p=.05)$, where younger people tended to estimate the duration as longer than older people.

\subsubsection{Additive Effects}

Comparisons of the four combinations of variables show the size of donations increase according to prediction in Hypotheses 3 and 4, as shown in Table 1. A graphical illustration of the table is provided in Figure 1, showing a consistent additive effect, with one exception.

A Tukey test on comparison between the four groups (Extent $\mathrm{x}$ Number) revealed significant differences between the conditions of High $\mathrm{x}$ High and the Low $\mathrm{x}$ Low $(\mathrm{p}=.01)$ and the High $x$ Low and Low $x$ Low $(p=.05)$. The mean differences between the conditions of High $x$ High and Low $\mathrm{x}$ High, as well as between High $\mathrm{x}$ Low and Low $\mathrm{x}$ High were not significant. This suggests that the variable extent-of-need has the greater impact of the two. Figure 3 graphically show how the two independent variables correlate with each other and how they impact on charity donation size (Charity1). Further clarification of the effects of the different conditions on mean amount of charity is found in Figure 2, where the 
two dependent variables (Charity1 and Charity3) were put side by side to illustrate a likely self-serving bias effect.

\subsection{Tables and Figures}

Table 1. Mean Amounts of Donation in Each Condition

\begin{tabular}{cccc}
\hline $\begin{array}{c}\text { Manipulation of } \\
\text { Needs: } \\
\text { Extent } x \text { Number }\end{array}$ & Charity1 & Charity2 & Charity3 \\
\hline 1. High x High & 143.30 & 643.30 & 128.70 \\
2. High x Low & 170.00 & 1386.70 & 151.30 \\
3. Low x High & 240.60 & 1931.30 & 269.40 \\
4. Low x Low & 292.80 & 2035.70 & 242.90 \\
Total & 210.80 & 1497.50 & 198.50 \\
\hline
\end{tabular}

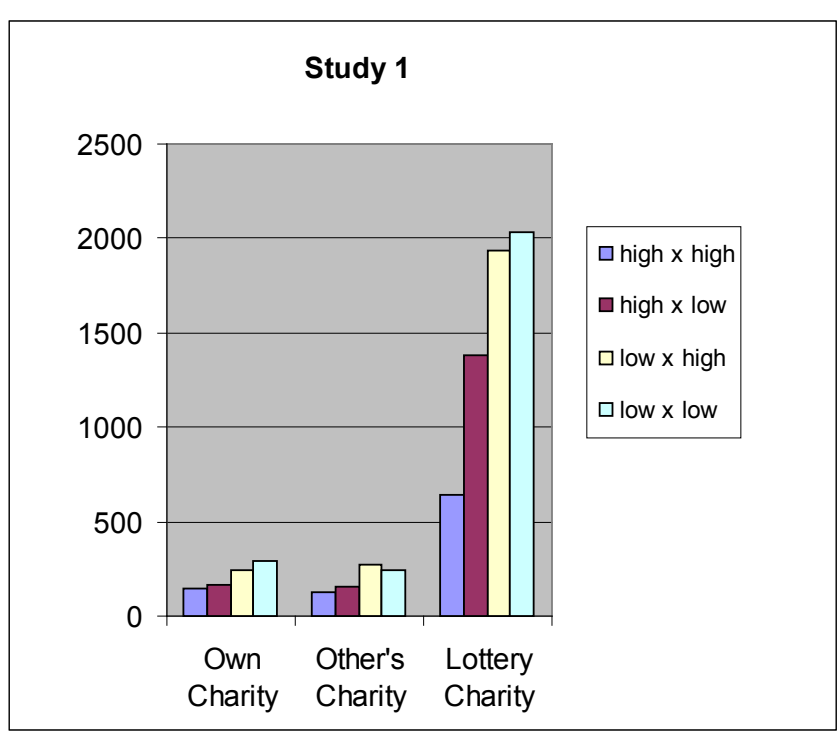

Figure 1. Mean amounts of donations in each condition

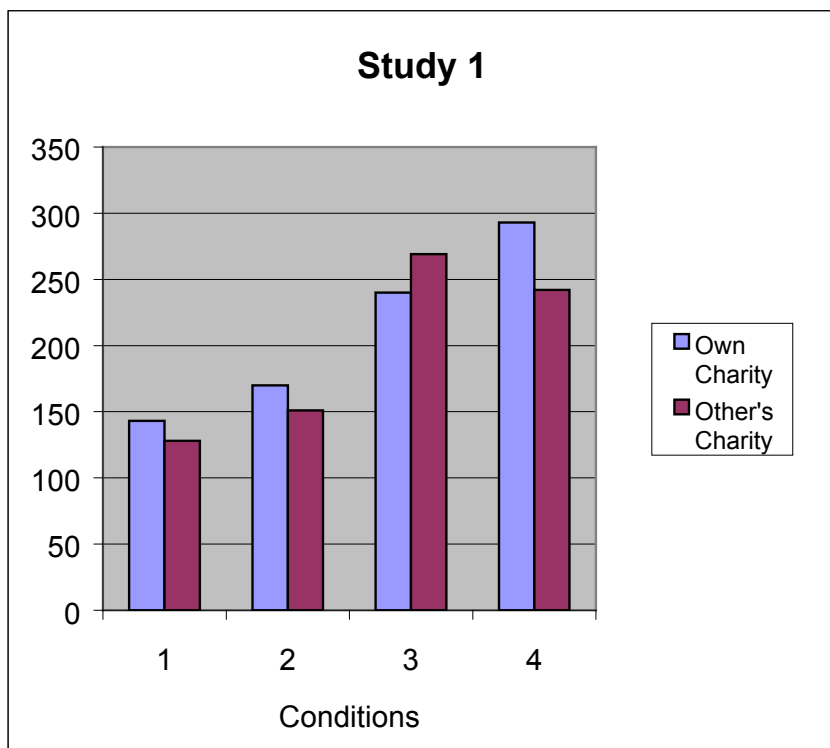

Figure 2. Mean amounts of own and other's charity in each condition

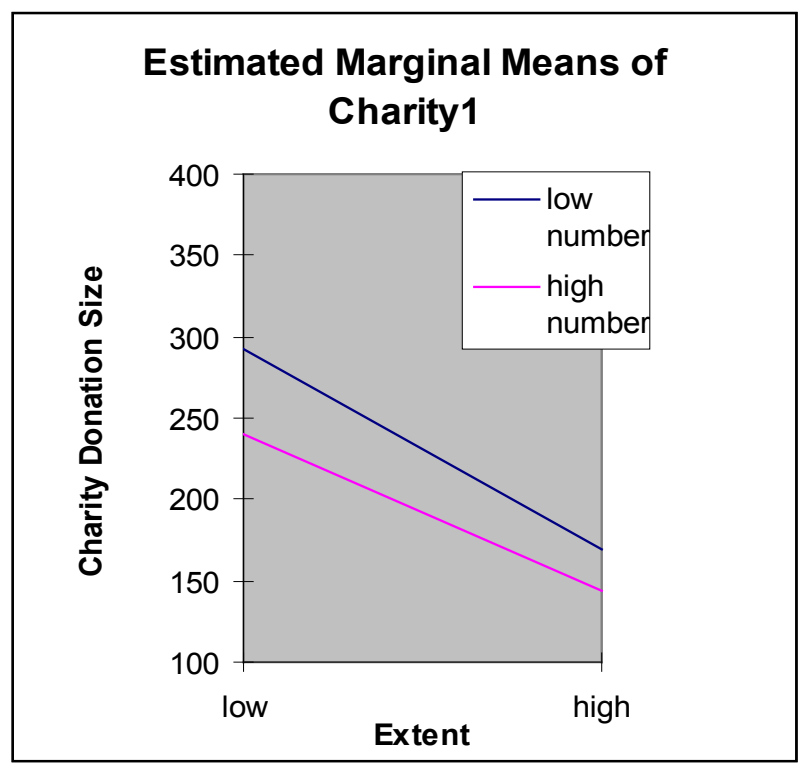

Figure 3. Mean of donations for Charity 1

\subsection{Discussion}

The main results of the data analysis showed that donations were smaller the greater the extent of need and the number of needs, thus supporting Hypothesis 1 and 2. When compared and analysed, the most powerful variable of the two was the extent of need. A simple explanation for this could be the variable was composed of two dimensions (time-duration and geographical area) making it more impacting. As predicted, the greater the relevance and amount of moral information, the less money was donated to charity. Also, the effectiveness of the manipulation of number of needs might have been decreased due to the introduction and contents of the letters being perceived as one great need, not giving room to heed to the amount of specific needs mentioned. The study showed that there is a correlation between the two factors and amount of money donated to charity: Subjects reading about high extent of need donated less than subjects reading about low extent of need, thus supporting Hypothesis 1. Secondly, subjects reading about a large number of needs donated less than subjects reading about a small number of needs, thus supporting Hypothesis 2. Additive effects according to predictions were also obtained between number and extent of needs. The high number and high extent condition produced the smallest donations, thus affirming Hypothesis 3. Finally, according to Hypothesis 4, the low number and low extent condition yielded the largest donation in two out of three cases, i.e. the measured charity variables (Figure 1). The findings seem for everyday intuition somewhat backwards; thinking the greater the need the more people would be inclined to help. This only adds to the flavour of the research, pointing further to the prospects of moral exhaustion.

Did the design produce the desired target of achieving various levels of information overload (moral exhaustion)? 
According to the measured variables the subjects were affected by the different levels of need, both in scope and number, resulting in significantly different behaviors. We might never know for sure whether the subjects really experienced tendencies of overload (conscious or unconscious), but we can label the correlation between increasing moral information and lessened helping as an information overload effect.

\section{Study II}

\subsection{Research Design}

In response to Study 1 not producing clear significant effects concerning the number of needs variable, a second shorter study was set up to possibly improve on the results and further support the findings of Study 1. Also, Study 2 would be helpful to establish a continuity of reliability, both for measurements as well as construct. The goal was to create a similar experimental situation using the same vignette technique as in the first design, while at the same time conducting the manipulation slightly differently. Again, the objective was to examine effects of information overload on charity donation, thus having to create a situation of cognitive overload, due to the reading about large amounts of needs (moral information). The choosing of scenario was a charity request situation, holding the context to charity giving to be able to closely compare the results of the studies. The focus in Study 2 was on what effect number of needs would have on charity donation size. This was derived from the mentioned theoretical relationship between amount of information and overload, predicted to lead to lessened engagement in helping. The hypotheses largely successfully supported in Study 1 were used with only slight modifications. The prediction for Study 2 was there would be a main effect of the number of needs on charity giving. The number of needs was this time manipulated in the form of lists of aid organisations, a long list (40 organisations) and a short list (4 organisations), where subjects was requested to pick out only one aid agency for donating charity. The assumption was subjects faced with a large number of aid organisations, (thereby indirectly being made conscious of a vast number of different needs), would be exposed to a greater information overload and consequently a diminishing of giving. The main hypothesis of the experiment would be stated as such: Subjects faced with a large number of aid organisations will donate less than subjects faced with a small number of aid organisations.

\subsection{Method}

\subsubsection{Subjects}

Another 44 undergraduate students $(12$ men and 22 women, ages 18-52), at the University of Skövde was handed charity letters describing a great need, followed by a list of aid organisations to choose from. Subjects were randomly assigned to one of two letters, i.e. long or short attached list of aid organisations.

\subsubsection{Materials}

Subjects received a fictional charity letter from an aid agency in Ethiopia, said to currently be monitoring and delegating resources in the ongoing crisis there. The letter described a scenario of extensive need in the country, followed by a request to donate charity to one aid-organisation to be picked out from an attached list. This time a situation well covered by media (specifically the plight of Ethiopian children) was chosen to attempt to increase the feelings of moral exhaustion. The letter conveyed the situation as being an urgent emergency, with those targeted as being innocent, and with the prospect of being significantly relieved if subject chose to help. The aim was to elicit feelings of empathy and willingness to help, while simultaneously creating exposure to moral exhaustion. There were two versions of the letters, differing only in the attachment, which listed aid organisations active in the targeted area. The letters contained a brief presentation of the situation, with vivid descriptions of the needs, ending with a request for reader to pick out one aid organisation from the attached list, to support with a one-time donation of money. The attachment varied in two versions, one lengthy with 40 names and one shorter with only 4 names. The aid organisations were of all sorts, differing in areas of expertise, scope, authority, and in being renowned. On a following sheet of paper, questions about perceptions of the letter were asked, later used for analysis. To ensure subjects' careful reading of the material questions concerning the contents of the letter and attachment were asked.

\subsubsection{Procedure}

Subjects were randomly assigned to one of two conditions of the charity donation form (Appendix B). A brief verbal introduction of it being a research survey measuring justice assessments in altruistic situations was made. No additional incentives were introduced, but for a promise with update on results. The study was carried out at the University of Skövde as part of class exercise.

\subsubsection{Dependent Variables and Manipulation Checks}

The measured main dependent variable was amount of money for donation (Charity), designated for aid in Ethiopia by subject's own choosing of aid organisation. To monitor the effectiveness of the manipulation the subjects were presented with a questionnaire form. The questions were answered on a scale ranging from 1 (very low) to 7 (very high) with formulations as such: How effective will your contribution to the aid in Ethiopia be? How difficult was it to choose one of the aid organisations? Again, in this study II, the difference in perceived effectiveness between the conditions were non-significant, $\mathrm{t}(42)=.08, \mathrm{p}=.93$.

\subsection{Results}

Average donation size for Charity in Swedish crowns was 
SEK277 ( $\mathrm{SD}=336, \mathrm{~N}=44)$. A comparison of means using a two-tailed T-test showed a significant main effect on donation size $(\mathrm{T}(42)=2.05, \mathrm{p}<.05)$, with means of SEK177 and SEK377, which line up well with the prediction of the hypothesis. Also, the Pearson's correlation between number of aid organisations and charity donation size was of significance, $(\mathrm{r}(42)=-.31, \mathrm{p}<.05)$. Responses to the items testing the effectiveness of the manipulation were analysed using a t-test. The impact of manipulating number of needs was checked by having the subjects rate their perception of the amount of needs in Ethiopia. The ratings did not yield a significant main effect, though the ratings in the high number of needs condition were higher $(\mathrm{M}=4.0)$ than those in the low number of needs condition $(\mathrm{M}=3.8)$. It is difficult to know what can be concluded from this check in terms of reliably strong effects.

\subsection{Discussion}

The results supported the finding from the first study that people on average gave less the greater the number of needs, this time with statistical significant effect. Reasons for succeeding better this time could be attributed to number of needs being varied more compared to Study 1 (40 to 4 items, compared to 6 to 2 items). A second point is the design differed by having subjects confronted with a choice of aid-organisation in the midst of the needy situation, making it more demanding. From the results it looks like the purpose of more eminent overload exposure was more successfully achieved by this design, but a question mark remains due to the failed effect on the manipulation check. The standard deviation and average donation size was also notably larger compared to Study 1 even though the context of charity letter was similar. It is difficult to speculate about reasons for this, but it is likely related to effects of personal choice of aid-organisation yielding larger variations in donations. In conclusion, the hypothesis of Study 2 was supported by the results and as predicted, the greater the information overload, the less money was donated to charity. The results show there is a correlation between the factors of number of aid organisations with amount of money donated to charity.

\section{General Discussion}

The expectation was that different quantities and qualities of a moral information would produce different levels of information overload, (thus implying moral exhaustion), which in turn would affect the inclination to help. As hypothesized, donations were more generous, when information focused on a few cases (low number of needs) rather than on many. Also, donations were more generous when the need was presented as an isolated incident both in time and geographical area. These findings were significant in spite of a relatively small number of subjects. These findings were also of significance regarding that the subjects didn't actually have to part with their money. It is likely that the proposed overload-effect would have been more prominent if people had to make real and not only simulated decisions. The finding of the follow-up study, which aimed at validating the first study, further confirmed the first hypothesis, this time with significant results. Also, these results support the findings of Warren and Walker that scope of need affects donation size, further establishing the link between moral information and altruistic behavior. Furthermore, the results could be seen as adding to the arguments of[21], proposing a relationship between scope of information and perceived effectiveness of helping, since donation size was found negatively correlated to scope of need. (Note though, in this study no such direct correlation between self-rated perceived effectiveness and scope was found). The unique contribution of the present study to this line of research is the finding about how amount of information (number of needs or aid-organisations) affected the intended helping, in this case the size of charity donation.

These seemingly contra-intuitive results (the greater needs, the lesser help) might be due to the possibility of feelings of overwhelmingness outweighing possible feelings of empathy, thus qualifying for the label information overload. The results suggest a lessened willingness and motivation to help experienced by people having to process information dealing with large numbers and extents of moral issues of delicate nature, like people suffering and needing help. Another explanation is the notion of perceived effectiveness of helping, stating subjects exposed to large numbers of needs simply judged their contribution to not affect the situation much and therefore chose a lesser amount. The control question on perceived effectiveness seems to speak against this notion. There were no significant differences in perception of effectiveness between the conditions, which give more credibility to the thesis of overload. Certainly this could be part of the explanation but is probably not the whole story, and it didn't show in the control question. Furthermore, written comments in the questionnaire in Study II revealed anguish over the predicament of the needy, stating they wished to be able to give much more. Further, the manipulations in the studies were sometimes perceptibly marginal, varying only between two and six items of need, still producing differences. Could there be a more emotional element inhibiting donation sizes, a state of overload depending in strength on the moral information received? The literature reviewed suggests processing difficulties and feelings of overwhelmingness can cause information overload, which in turn can lead to decreased efficiency and emotional exhaustion. Perhaps the greater the extent and number of needs, the more difficult to process the information, the perceived injustices and the dissonance contrasted to own well being, which is measurable through decreasing donation sizes? Also, perceiving your own lack of effectiveness of helping the greater the need probably strengthens the emotions of information overload, only adding to the effects of moral exhaustion. A combination of information overload due to moral information with an assessment of inability to relieve is likely the path towards experienced moral exhaustion. Further research on these issues needs to be done. The conclusion for now is the 
finding of the two studies that different levels of moral information can have inhibiting effects on charity giving and that this phenomenon, according to literature and analysis, is a form of information overload, which could be labelled moral exhaustion.

Other findings of a more post-hoc nature were the difference between men and women in believed donation size by others to aid-organisations, as well as self-reported changes in mood due to the charity letters. Were women more affected by the information in the letter or were they just more honest in their reporting? Do women believe better of others than men? The second study showed similar differences, but were not reported due to non-significant effects.

Furthermore, age differences were obtained concerning perception of duration of need and perception of own ability to impact the need-situation. Concerning perceived effectiveness, it is interesting to note the indicators that the older the subjects, the more they felt they had an impact in helping relieve the needs. One suggestion is with age and experience a sense of general responsibility for others increases and in a situation like giving aid; the sense of responsibility might distort the perception of effectiveness of own charity donation, through dissonance-reducing mechanisms.

A final minor finding that deserves attention is the familiar self-serving-bias effect, suggested via comparison between how much people gave with how much they believed others would give (Figure 2). The impact of extent and number of needs turned out to be less on the amount others were believed to give. One explanation for this could be people were inclined to give more careful thought and analysis when deciding about the amount they themselves would give, thus depending more on the information in the letter and thereby being affected more.

The results of this study have important implications for fund raising strategies. The common assumption seems to be the more emphasis on the duration, scope and number of needs, the larger the donations. The results of the present study are contradictory to this--prosocial behavior was inhibited by such an emphasis. Thus, if the purpose is to enlarge and maximize charity donations, the extent and number of needs must be downplayed while other factors such as severity and emergency of need should be emphasized. Social psychology, within this area of exhaustion and overload, will have much to say concerning these issues in the future.

Lastly, a more general discussion point to be made out of these studies is the way the media (commercials, charity, politics etc) is utilized for the purpose of changing and controlling people's behavior. For instance, by repeatedly exposing to extensive imagery of opinions or behavior through TV, such as violence or injustices, serves more to pacify people and inhibit own initiatives, than contrary? Similarly, a focus on great numbers (of needs, wars, followers etc) may lead people into states of helplessness and perceived ineffectiveness instead of encouraging action?
Certainly, dictatorial regimes have long made use of these kinds of strategies, but what happens in our own backyards concerning opinion changes, exploitations of consumers, or political control? We should ask ourselves if and how information overload and moral exhaustion are affecting us? Research on moral exhaustion seems to demand our attention and many interesting discoveries is to be made in the future.

\section{ACKNOWLEDGEMENTS}

I'd like to thank the now emeritus professor, Kjell Törnblom, for being kind and approachable for the masters' students of Skovde University.

\section{REFERENCES}

[1] Shenk, David (1997). Data Smog - Surviving the Information Glut. San Francisco. California. Harper Edge.

[2] Reuters (1997). Dying for Information. London. Reuters.

[3] Kirsh, David (2000). A few thoughts on cognitive overload. Intellectica 2, 24-29.

[4] Abbott, Robert (1999). The World as Information. Wiltshire, England, Cromwell Press.

[5] Milgram, Stanley (1970). The experience of living in the cities. Science 3, 1461-68.

[6] Wurman, Richard S. (1989). Information Anxiety. New York. Doubleday.

[7] Maslach, Christina (1986). Burnout. Stockholm. Natur \& Kultur.

[8] Freudenberger (1974). Staff burnout, Journal of Social Issues 30, 159-165.

[9] Jurisoo, Mart (2001). Burnout. Stockholm. Ekerlid.

[10] Lewis, David (1997). Information Overload. London. England. Richters.

[11] Schaffer, David R. (1996). Development Psychology. Pacific Grove, California. Brooks/Cole Publishing.

[12] Bandura, Al (1999). Moral disengagement, Personality and Social Psychology Review 3, 193-209.

[13] Opotow, Susan (2000). Moral exclusion. Journal of Social Issues 56, 475-490.

[14] Schroeder, David (1995). The Psychology of Helping. New York. McGraw-Hill.

[15] Maslach \& Leiter (1999). The Truth about Burnout. Stockholm. Natur \& Kultur.

[16] Rosenthal, A.M. (1964). Thirty-eight Witnesses. California. University of California Press.

[17] Latane, B. \& Darley, J. (1970). The Unresponsive Bystander. New York. Prentice-Hall.

[18] Aronson, Elliot (1999). Social Psychology. New York. 
[19] Warren, Peter \& Walker, Ian (1991). Empathy, effectiveness and donations to charity. British Journal of Social Psychology 30, 325-337.

[20] Finch, Janet (1987). The vignette technique in survey research. Sociology 21,105-114.
[21] Miller, Dale T. (1977). Altruism and threat to a belief in a just world. Journal of European Social Psychology 13, 113-124.

[22] Korte, C., Ypma, I., \& Toppen, A. (1975). Helpfulness in Dutch society as a function of urbanization and environmental input level. Journal of Personality and Social Psychology, 32(6), 996. 